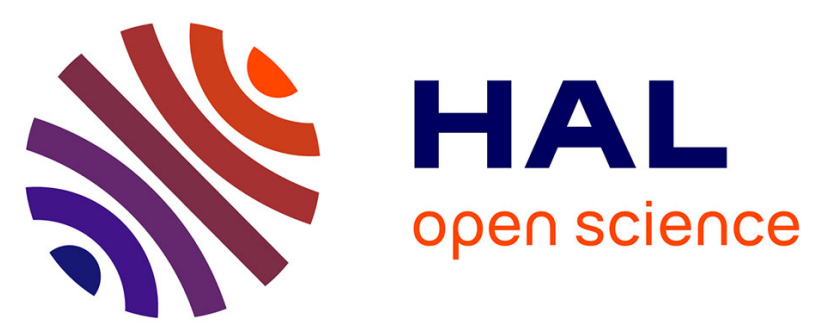

\title{
Intersected Octree Conformal Grid Strategies for Applications to Aeroacoustic Computations of the LAGOON, Landing Gear Model, using the CEDRE unstructured Flow Solver
}

François Vuillot, Sâm Landier, Thomas Renaud, Christophe Benoît, Laurent Sanders

\section{To cite this version:}

François Vuillot, Sâm Landier, Thomas Renaud, Christophe Benoît, Laurent Sanders. Intersected Octree Conformal Grid Strategies for Applications to Aeroacoustic Computations of the LAGOON, Landing Gear Model, using the CEDRE unstructured Flow Solver. 25th AIAA/CEAS Aeroacoustics Conference 2019, May 2019, DELFT, Netherlands. 10.2514/6.2019-2483 . hal-02292873

\section{HAL Id: hal-02292873 https://hal.science/hal-02292873}

Submitted on 20 Sep 2019

HAL is a multi-disciplinary open access archive for the deposit and dissemination of scientific research documents, whether they are published or not. The documents may come from teaching and research institutions in France or abroad, or from public or private research centers.
L'archive ouverte pluridisciplinaire HAL, est destinée au dépôt et à la diffusion de documents scientifiques de niveau recherche, publiés ou non, émanant des établissements d'enseignement et de recherche français ou étrangers, des laboratoires publics ou privés. 


\title{
Intersected Octree Conformal Grid Strategies for Applications to Aeroacoustic Computations of the LAGOON, Landing Gear Model, Using the CEDRE Unstructured Flow Solver
}

\author{
François Vuillot ${ }^{1}$, Sâm Landier ${ }^{2}$, Thomas Renaud ${ }^{2}$, Christophe Benoît ${ }^{2}$, Laurent Sanders ${ }^{2}$ \\ ONERA, University of Paris-Saclay, F-92322 Châtillon, France
}

\begin{abstract}
Introduction and context
Aircraft noise is a societal concern and landing gears contribute significantly to the generated noise in approach and landing configurations. Landing gears are characterized by their complex geometry and numerous works have been carried out to develop and validate aeroacoustics simulations to predict the associated noise (e.g. [1], [2]). Most of them associate a time resolved flow solution, to capture the acoustic sources, to an acoustic computation, to estimate the resulting far field noise. Due to the geometric complexity, unstructured grids are required and may necessitate meticulous work to optimize (e;g. [3], [4], [5]). In this context, Lattice Boltzmann Methods (LBM) have become popular as they propose to combine automatic grid generation and high CPU efficiency and produced remarked results (e.g. [6], [7]). The automatic grid generation is facilitated by the use of advanced wall models that do not require resolution of complex details of boundary layer flow, ranging from attached to detached regimes, that are produced by the complex geometries and flow environment of landing gears. Navier-Stokes (NS) solvers on the contrary rely on precise boundary layer solution that require complex grids, even in the unstructured approach, to handle the attached boundary layer regimes, that require strong grid anisotropy, as well as detached regimes and their trailing flow, that require grid isotropy. The grid construction work can therefore become a complex process. The simplification of this process is then an important challenge for industrial applications. The present work details a multi-year effort at ONERA in that direction.
\end{abstract}

\section{Objective}

The present effort aims at demonstrating the interest of some automatic grid generation strategies for NS solvers while preserving the detailed boundary layer flow solution. The present approach focuses on the details of the matching region where the automatically generated grid merge with the boundary layer grid generated around the landing gears geometry. In that sense the present work can be viewed as an alternative to the present efforts on immersed boundary conditions (IBC, [8]), described elsewhere, where the background grid directly intersect the landing gears body. In the present paper, the LAGOON (LAnding Gear nOise database for CAA validatiON) test case is retained. The LAGOON project, founded by AIRBUS, and involving ONERA, DLR and University of Southampton, aimed at providing an extensive database of flow and noise measurements for the development of new CFD/CAA strategies for landing gear noise predictions. The geometry used is based on a highly simplified 2:5 scaled AIRBUS single aisle aircraft nose landing gear. It was extensively tested for both aerodynamics and aeroacoustics measurements at ONERA's F2 and CEPRA19 wind tunnels [9], [10]. The basic configuration was then proposed in the framework of the AIAA BANC international workshop and has been computed by several teams [2]. The geometry of the LAGOON landing gear is presented in Figure 1.

\footnotetext{
${ }_{1}^{1}$ Scientific advisor, Multi-Physics for Energetics department: francois.vuillot@onera.fr

${ }^{2}$ Research scientist, Aerodynamics, Aeroelasticity, Acoustics department 


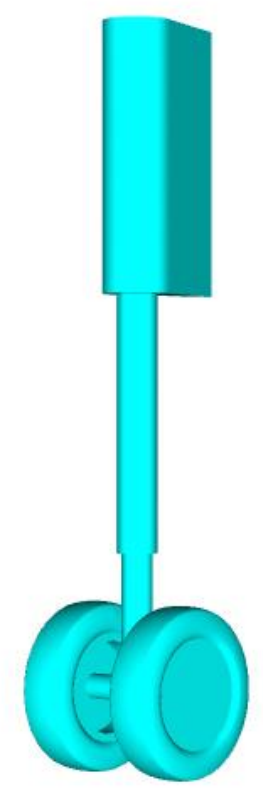

Figure 1: LAGOON baseline configuration.

\section{Methods}

This section presents the ONERA tools that were used in the present effort. They have been used in a number of past works, demonstrating their ability to produce high quality aerodynamic and acoustic results. First the aerodynamic flow is computed using the ONERA in house CEDRE code which is a multi-physics, fully unstructured solver, developed at ONERA with main applications in the energetics and propulsion fields [11], [12]. It is based on a cell centered finite volume approach that deals with generalized polyhedral grids (cells can have any number of faces and faces can have any number of vertices). Its Navier-Stokes solver, CHARME, relies on spatial discretization based on second order MUSCL schemes and time integration schemes based on explicit or implicit GMRES schemes (up to third order). Several turbulence models are available, ranking from one-equation or twoequations RANS models, to LES Smagorinsky models and ZDES hybrid RANS-LES approach. The computations performed in the present paper were run with the ZDES approach [13], [14], based on a SA (Spalart-Allmaras) RANS model. This methodology has been applied to several landing gear configurations and proved to provide very satisfactory results [15], [16], [17], [5].

The ZDES wall pressure is stored on the landing gear surface and is subsequently used in an acoustic postprocessing step, to reconstruct the far field noise, relying on a Ffowcs-Williams and Hawkings approach (FW-H), available in the ONERA in house KIM code [18], [19].

In the present work, in continuation of the previous paper [25], the ONERA Cassiopée tool [20] is used to automatically generate the computational grid. Starting from a surface grid that includes all the desired refinements to describe the flow around the landing gear geometry, the Cassiopée software is used to first generate the prisms layers around the landing gear surface, with a prescribed prism height distribution and then to generate an automatic octree grid, based on specified grid size in different regions of the computational domain. The particular options to handle the conformal matching between the two independently generated grids are discussed later on. 


\section{Past work}

Two grid strategies are considered as detailed in the previous work presented in 2017 [25]. The first one is the simplest where the background grid is based on an octree grid that is interrupted before reaching the landing gear body and its attached boundary layer grid made of prismatic layers, the gap being filled by tetrahedra, much like the Dragon grid strategy [22], [23]. The second strategy, with great benefit in the total cell count by removing the tetrahedra of the dragon approach, is to simply let the octree grid intersect the prismatic layers. In both strategies, the resulting grid is handled by the generalized polyhedral approach available in the CHARME NS solver, that treats all particular cells generated in the grid generation process, either the octree refinement, where one cubic cell is matched to four smaller cubic cells, or the intersected cells, as polyhedral cells in a fully conservative way. It must be emphasized that the second, intersected approach, generates complex, potentially concave, cells that present a challenge for the NS solver. In the previous work [25] that challenge was not properly handled and the corresponding computation could not be carried out, due to solver instability at these particular cells, that led to strongly reduce the computation time step and hence increased the total CPU cost. As a consequence the previous work could only conclude on the fist, dragon like approach, the second one being left to further treatment of problematic concave cells, which is the subject of the present paper.

\section{Present work}

The present work will detail and comment recent progress made on the second approach. First the intersection module was enhanced by a regularization of concave cells and the NS solver was upgraded in its treatment of polyhedral cell definition, allowing a robust cell definition and face orientation. This permitted to carry out the second strategy to completion from aerodynamic flow solution to acoustic far field computations. In addition the previous dragon grid approach was revisited with a refined background grid (grid OM13). These new results are rapidly presented in the present abstract and will be detailed and discussed in the final paper. Table 1 below summarizes the different grids that were used in the present effort.

Table 1: Grids and cell counts

\begin{tabular}{|l|c|c|c|c|c|}
\hline & OM11 & OM12 & OM13* & OM21** & OM22* \\
\hline prisms & $16 \mathrm{M}$ & $19 \mathrm{M}$ & $20 \mathrm{M}$ & $16 \mathrm{M}$ & $16 \mathrm{M}$ \\
\hline $\begin{array}{l}\text { polyhedra (octree and cut } \\
\text { cells for OM2i) }\end{array}$ & $2 \mathrm{M}$ & $4 \mathrm{M}$ & $6 \mathrm{M}$ & $6 \mathrm{M}$ & $6 \mathrm{M}$ \\
\hline tetrahedra & $12 \mathrm{M}$ & $12 \mathrm{M}$ & $12 \mathrm{M}$ & - & - \\
\hline Total & $30 \mathrm{M}$ & $35 \mathrm{M}$ & $38 \mathrm{M}$ & $22 \mathrm{M}$ & $22 \mathrm{M}$ \\
\hline
\end{tabular}

$*$ : new grids constructed for the present paper.

** : OM21 did not produce valuable results [25].

It is worth to mention that the present OM22 grid is based on previous octree definition of OM12 and that the identical polyhedra count with the refined OM13 grid is simply coincidental as it includes both the octree (hexahedra) and the real polyhedra resulting from octree refinements and cut cells resulting from the intersection work for the OM2i grids. The fact that OM21 and OM22 grids show the same cell count is due to the relative small number of the regularized cells of the OM22 grid. Figure 2 illustrates the general grid topology generated by the Cassiopée octree grid generation module.

These cell counts can be compared to the previous G1 and G2 unstructured grids that were especially tailored to the flow physics of the LAGOON landing gear [17], see Table 2. 
Table 2: Grids and cell counts of previous work [17]

\begin{tabular}{|l|c|c|}
\hline & \multicolumn{1}{|c|}{ G1 } & optimized G2 \\
\hline prisms & $20 \mathrm{M}$ & $19 \mathrm{M}$ \\
\hline $\begin{array}{l}\text { polyhedra (octree and cut } \\
\text { cells for OM2i) }\end{array}$ & - & - \\
\hline tetrahedra & $42 \mathrm{M}$ & $43 \mathrm{M}$ \\
\hline Total & $62 \mathrm{M}$ & $62 \mathrm{M}$ \\
\hline
\end{tabular}

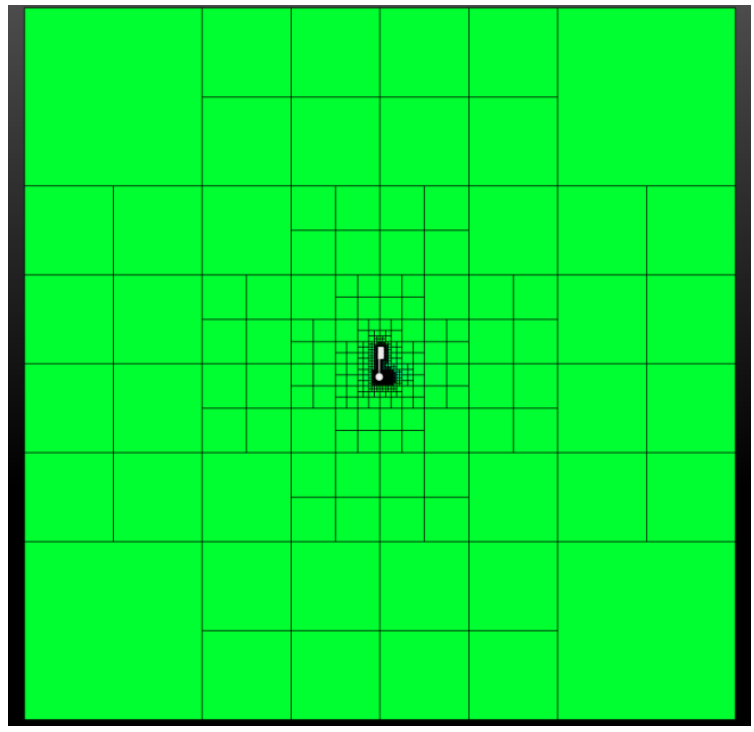

Figure 2: overall grid topology from OM grids

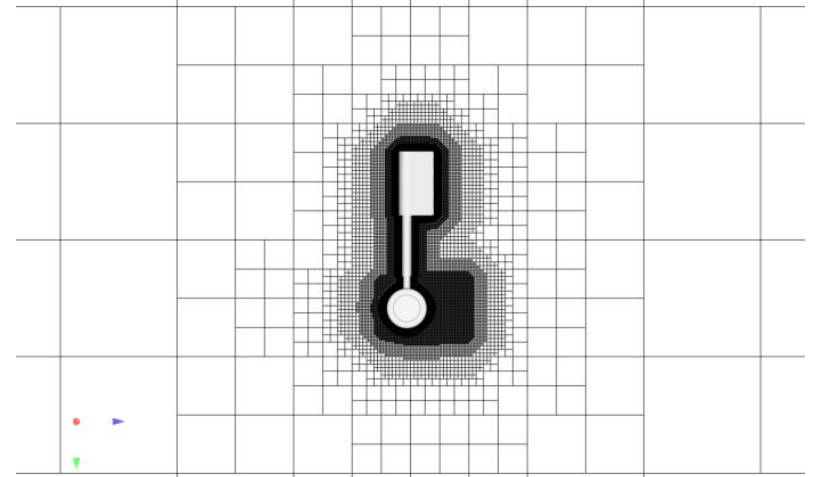

OM13 grid

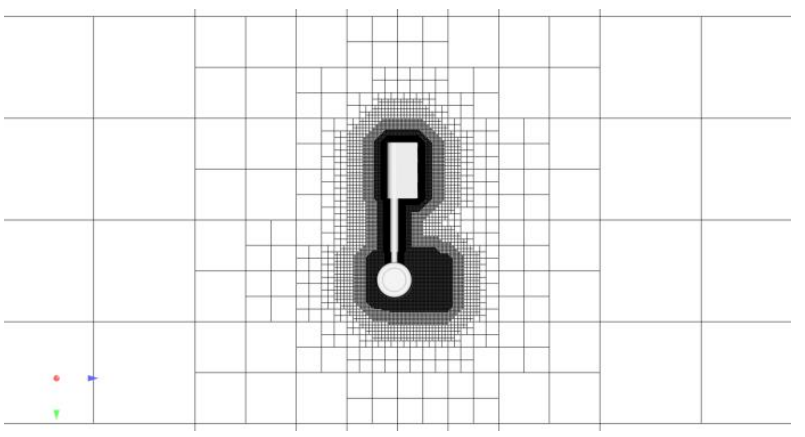

OM22 grid

Figure 3: overall grid topology from OM13 and OM22 polyhedral dragon grids

These overall octree grid requirements being specified, two strategies are being considered to complete the computational grid. The first strategy, grids termed OM1i, will proceed in filling the gap between the octree grid internal boundary and the prism layers external boundary with tetrahedra, much like the dragon grid strategy exposed in [22], [23]. The second strategy, grids termed OM2i, will directly intersect the octree grid with the prismatic boundary layer grid. Several grids were generated, for different maximum resolution in the inter-wheel cavity and landing gear close vicinity. OM12 and OM22 share the same octree grid definition while OM13 benefits from a refined definition in the inter-wheel cavity. Figure 3 presents general views of the OM13 and OM22 grids 
used in the present paper and Figure 4 show the details in the vicinity of the LAGOON wheels. This figure can be compared to Figure 5 which shows the previous grid G2. These figures illustrate the differences of the considered grids in the inter-wheel and wake regions which may have some importance on the final results. Close-up views of the different matching approaches are illustrated by Figure 6 and Figure 7, respectively for the intersected and dragon approaches.

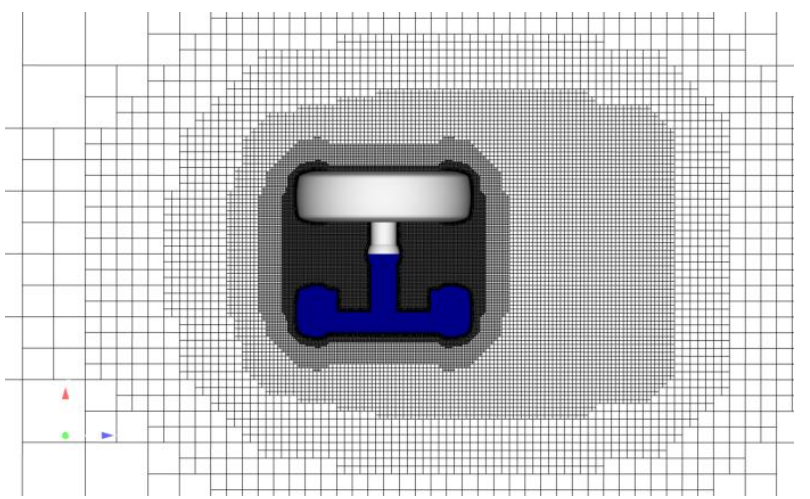

OM13

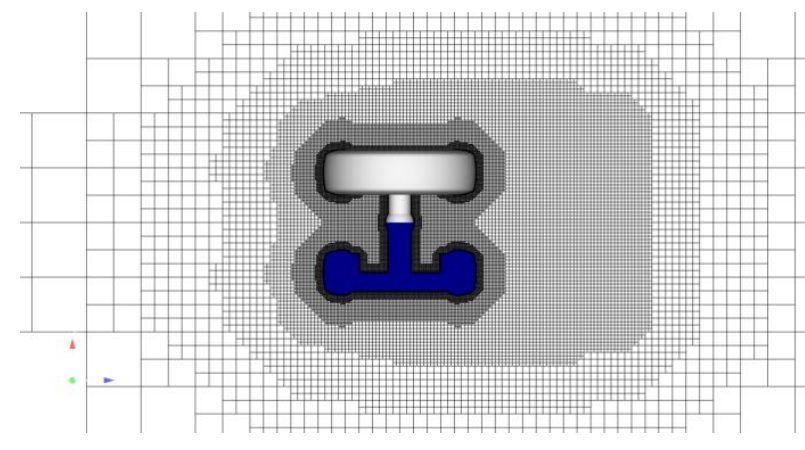

$\mathrm{OM} 22$

Figure 4: Detailed view around the landing gear wheels for OM13 and OM22 grids

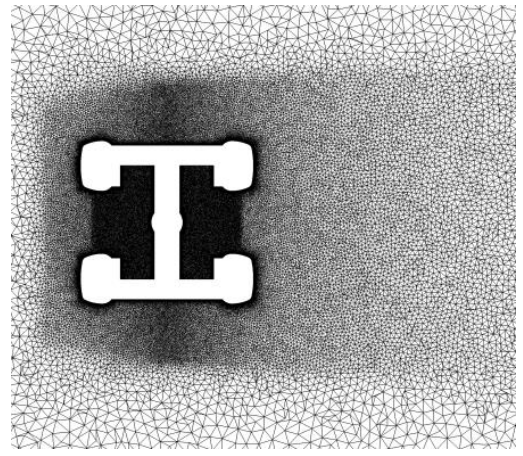

Figure 5: Detailed view around the landing gear wheels for G2 grid

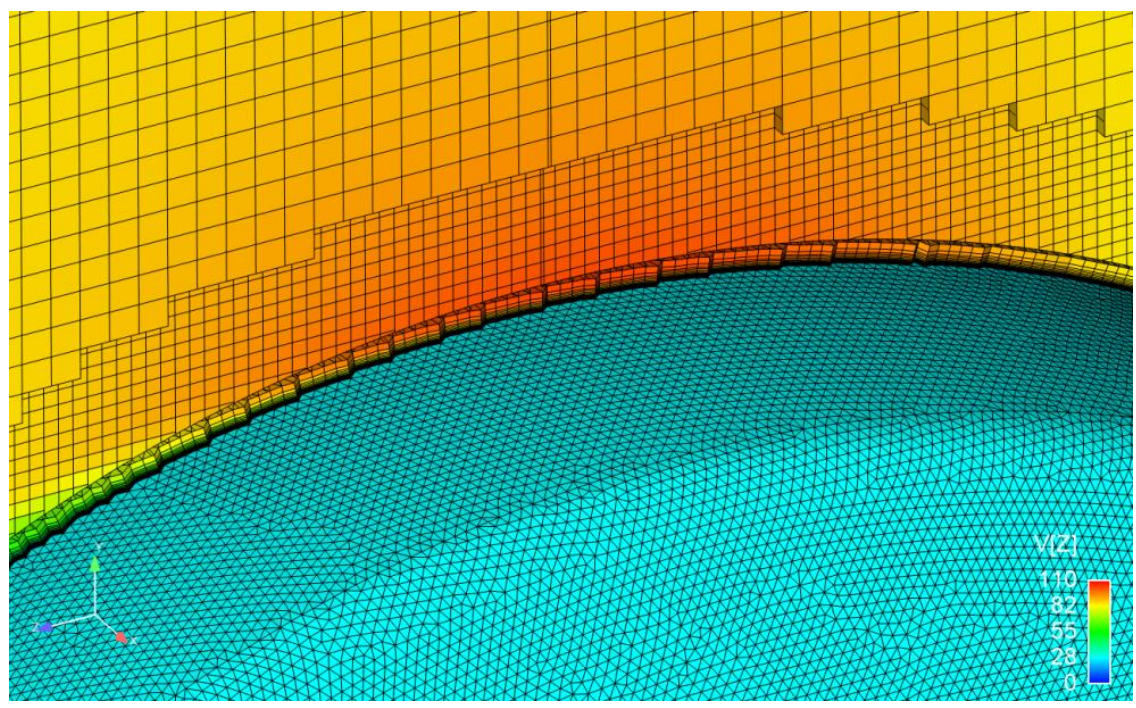

Figure 6: Details of the OM22 grid

American Institute of Aeronautics and Astronautics 


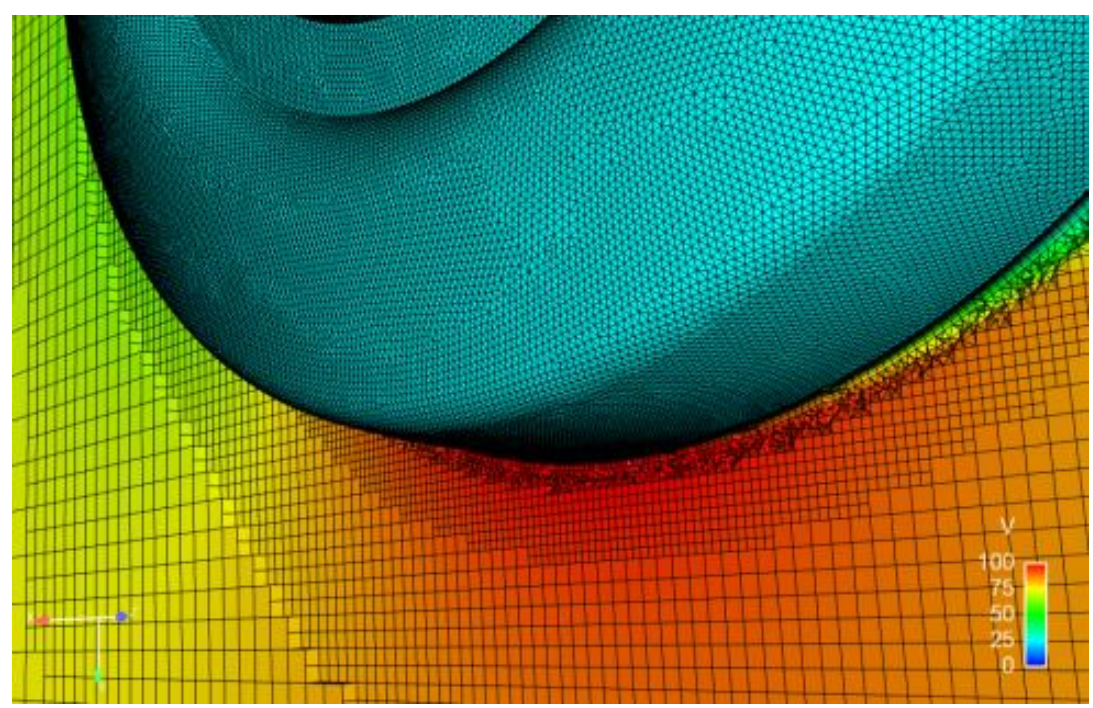

Figure 7: Details of the OM13 grid

\section{New results}

This paragraph will quickly illustrate the new results obtained. The computations were run until overall flow establishment was achieved. As proposed in [5] one convenient indicator of flow establishment is the main effort on the landing gear body, represented by the drag coefficient. A total of $300 \mathrm{~ms}$ were computed and the last $120 \mathrm{~ms}$ were used for flow statistics, PSD computations and acoustics computations.

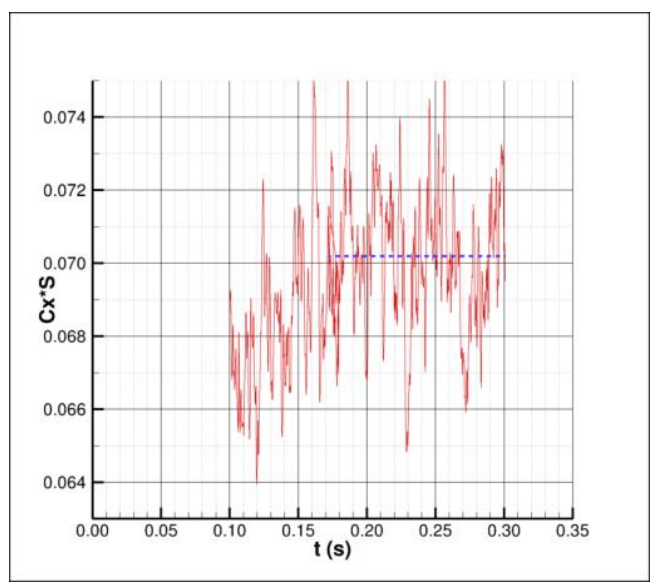

Figure 8: Convergence history of OM22 computation from computed drag on the Lagoon wall

\section{A. Mean aerodynamic results}

First the computed Cp distributions around the left wheel for the OM12 (OM13 still to be processed) and OM22 grids are compared to measurements on Figure 9. Then Figure 10 presents the mean velocity profile from the left wheel at the $90 \mathrm{deg}$. position, compared to measurements for OM12 and OM22 computations. These figures illustrate the good agreement obtained and that both grid definition produce a good description of the mean aerodynamic field. 
Abstract submitted to the 25th AIAA/CEAS Aeroacoustics Conference, Delft, 20-24 May 2019
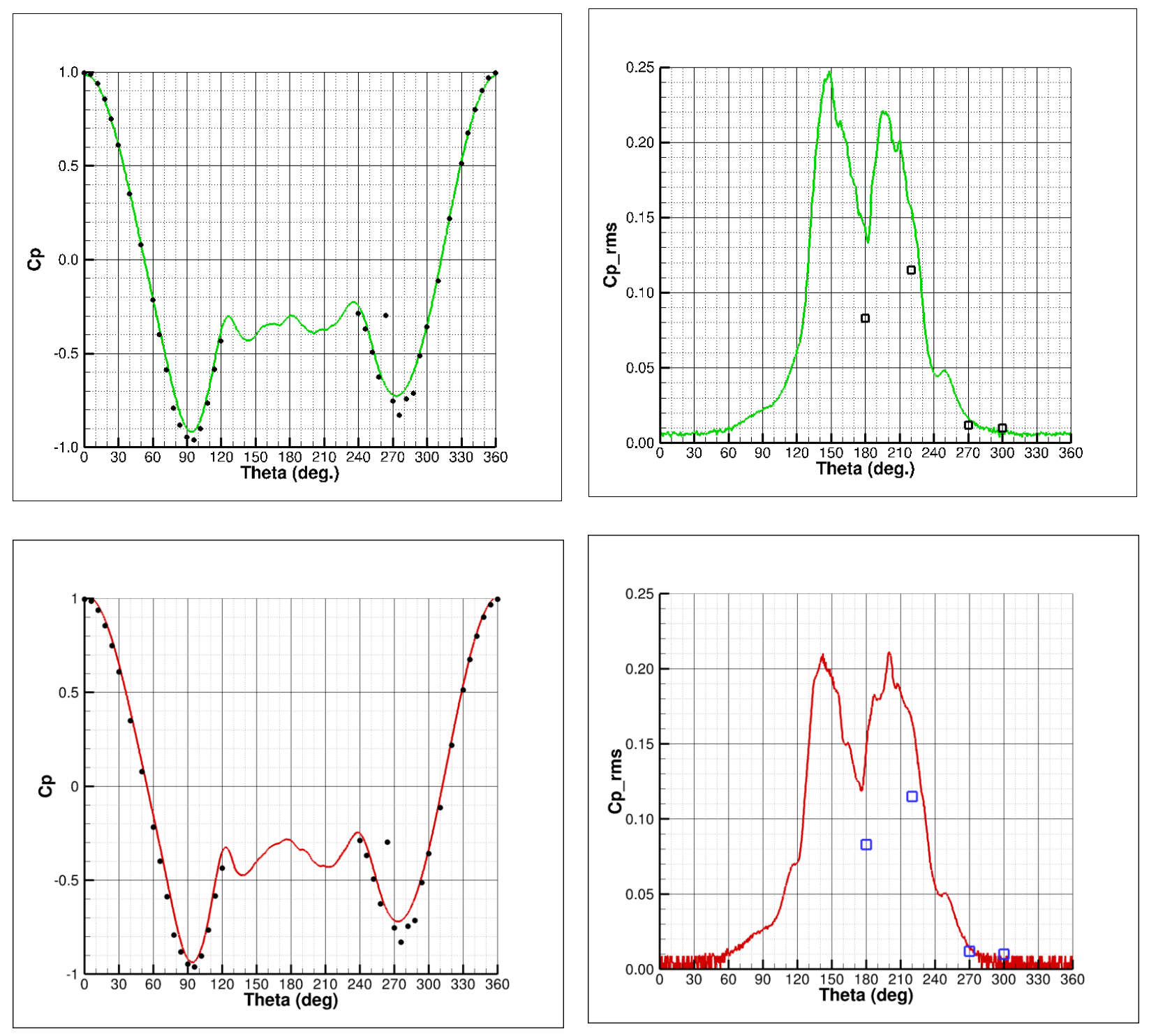

Figure 9: Pressure distribution along the left wheel. Solid line computation OM12 (top), OM22 (bottom), symbols measurements. Cp (left); Cp_rms (right) 

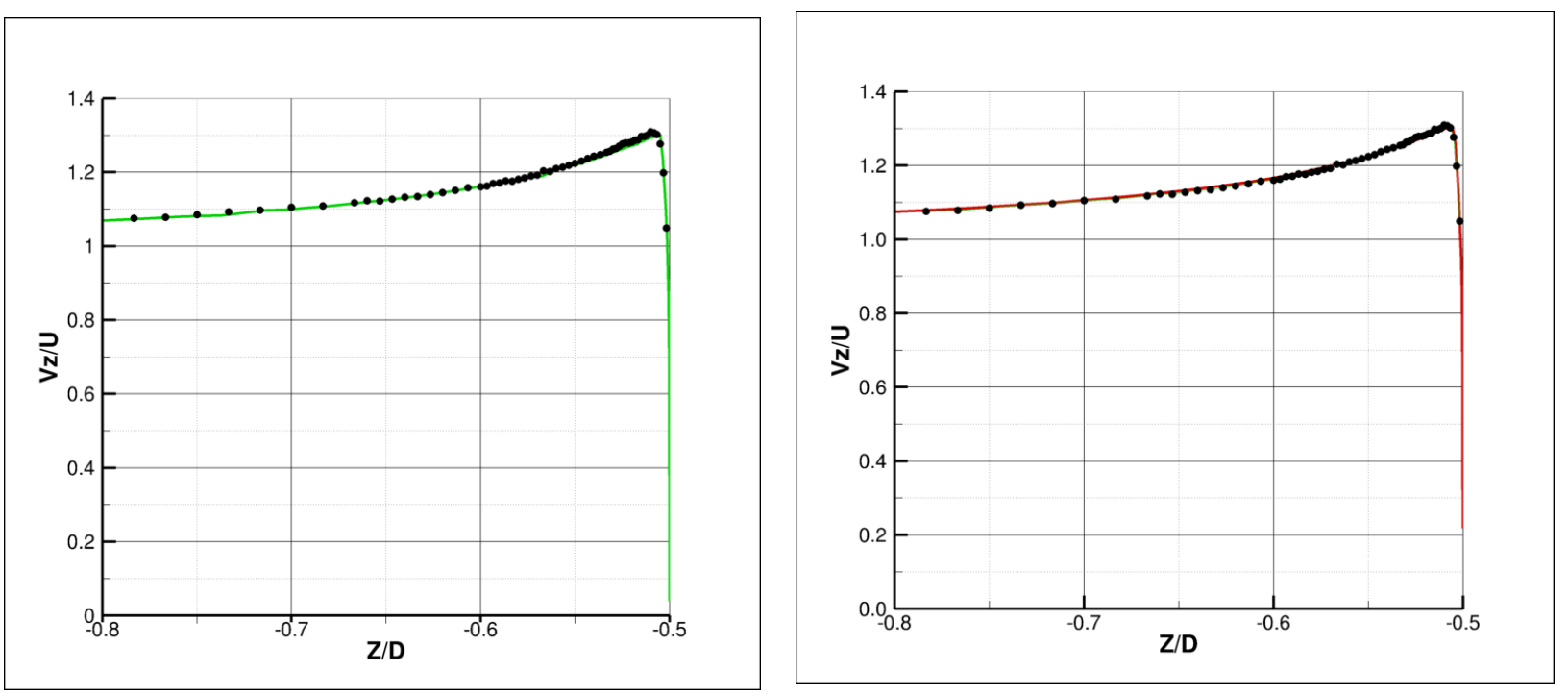

Figure 10: Velocity profiles from the wheel at the theta=-90 deg. position. Solid line computation OM12 (left), OM22 (right), symbols measurements.

Next, Figure 11 and Figure 12 present the comparison of the OM12 and OM22 mean and RMS velocity maps at the $\mathrm{Z}=0$ position behind the wheel, compared to the available PIV measurements. Again very satisfactory agreement is observed. 

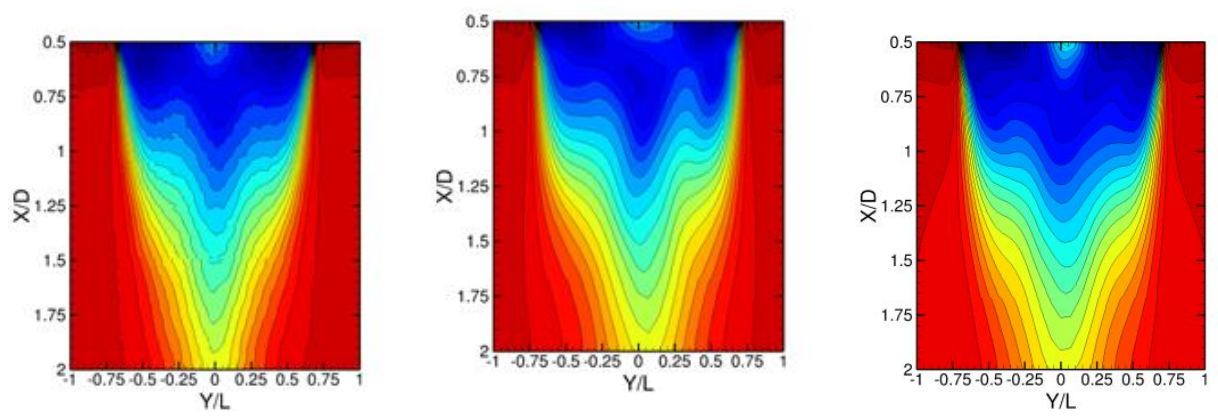

$\mathrm{U} / \mathrm{U}_{\infty}$

1.100

1.000

0.900

0.800

0.700

0.600

0.500

0.400

0.300

0.200

0.100

0.000
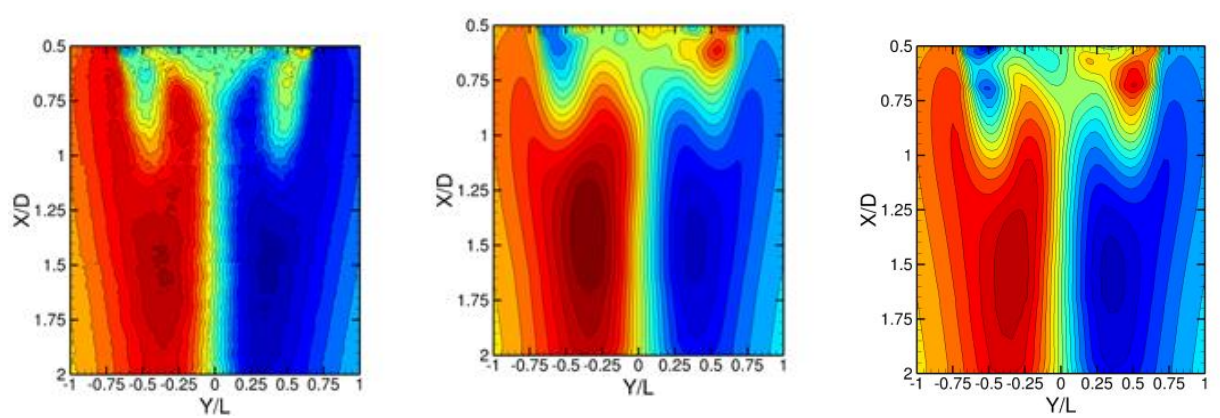

$\mathrm{V} / \mathrm{U}_{\infty}$

0.250

0.200

0.150

0.100

0.050

0.000

$-0.050$

$-0.100$

$-0.150$

$-0.200$

$-0.250$

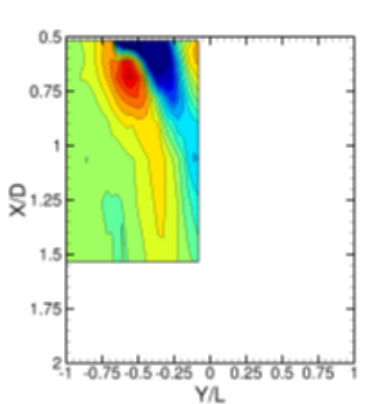

Experimental PIV

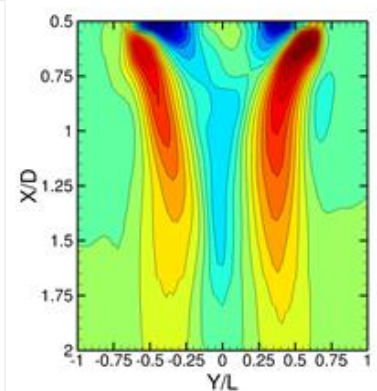

Computation OM12

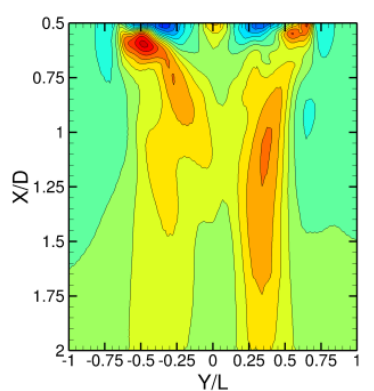

Computation OM22
$\mathrm{W} / \mathrm{U}_{\infty}$

0.250

0.200

0.150

0.100

0.050

0.000

$-0.050$

$-0.100$

$-0.150$

$-0.200$

$-0.250$

Figure 11: Mean velocity maps at the $Z=0$ plane, $0 M 12$ and $0 M 22$ 

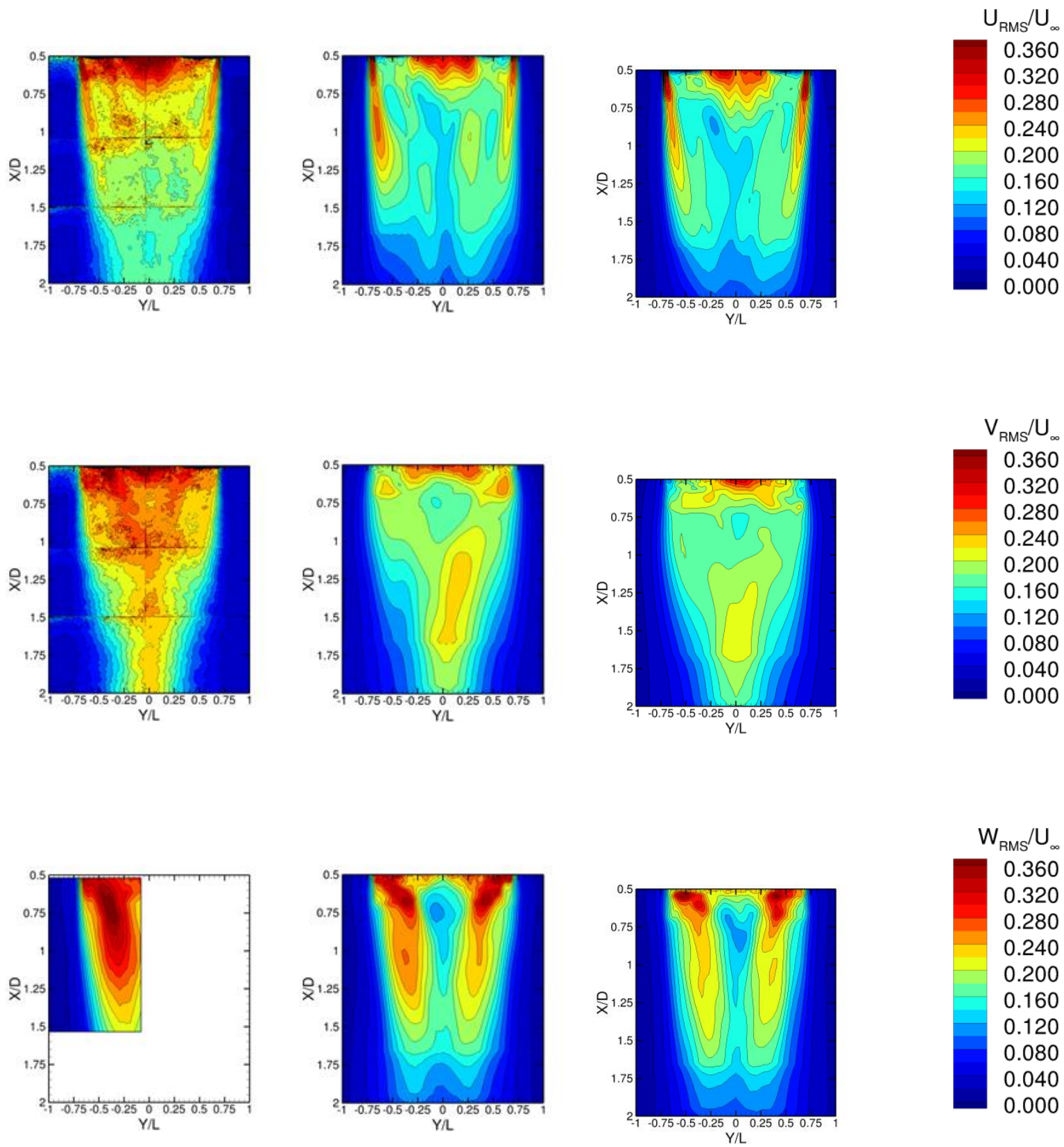

Experimental PIV Computation OM12

Computation OM22

Figure 12: RMS velocity field at the $Z=0$ plane, $0 M 12$ and $0 M 22$ 


\section{B. Unsteady pressure on the LAGOON wall}

During the experimental campaigns, unsteady wall pressures were recorded at several locations on the landing gear skin, as summarized on Figure 13 below.
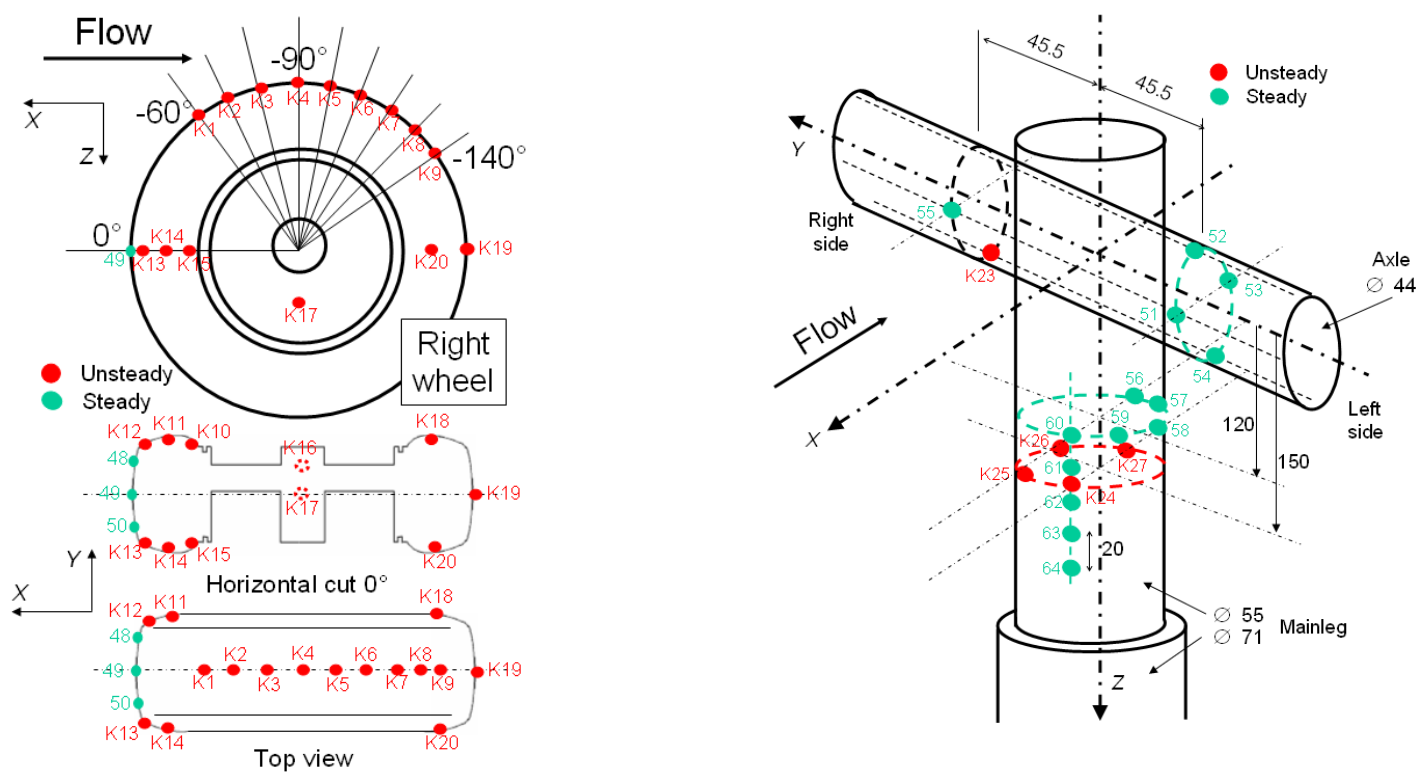

Figure 13: experimental pressure transducer locations

Power Spectral Density (PSD) computed (using 11 overlapping blocks and Hann windowing) from the $120 \mathrm{~ms}$ of available unsteady wall pressure with the different grids are illustrated on Figure 14 and Figure 15 for selected pressure transducers. Figure 14 presents the PSD of pressure signals recorded along the right wheel (see Figure 13) and shows an overall satisfactory agreement, from pressure sensors pk01, pk04, pk09 and pk19, in terms of observed levels and presence of frequency peaks at 1000 and $1500 \mathrm{~Hz}$. Figure 15 presents the PSD of pressure signals recorded at other locations (pk15, pk17, pk20 and pk23). Again an overall satisfactory agreement is observed. Good comparison with the previous computation of grid G1 is also observed, except for a consistently smaller cut-off frequency which results from the coarser grid definition of the octree grids used in OM computations. The better results observed for the pk15 transducer is attributed to a finer surface grid size for the OM grids in this critical flow area, where the flow detaches. 

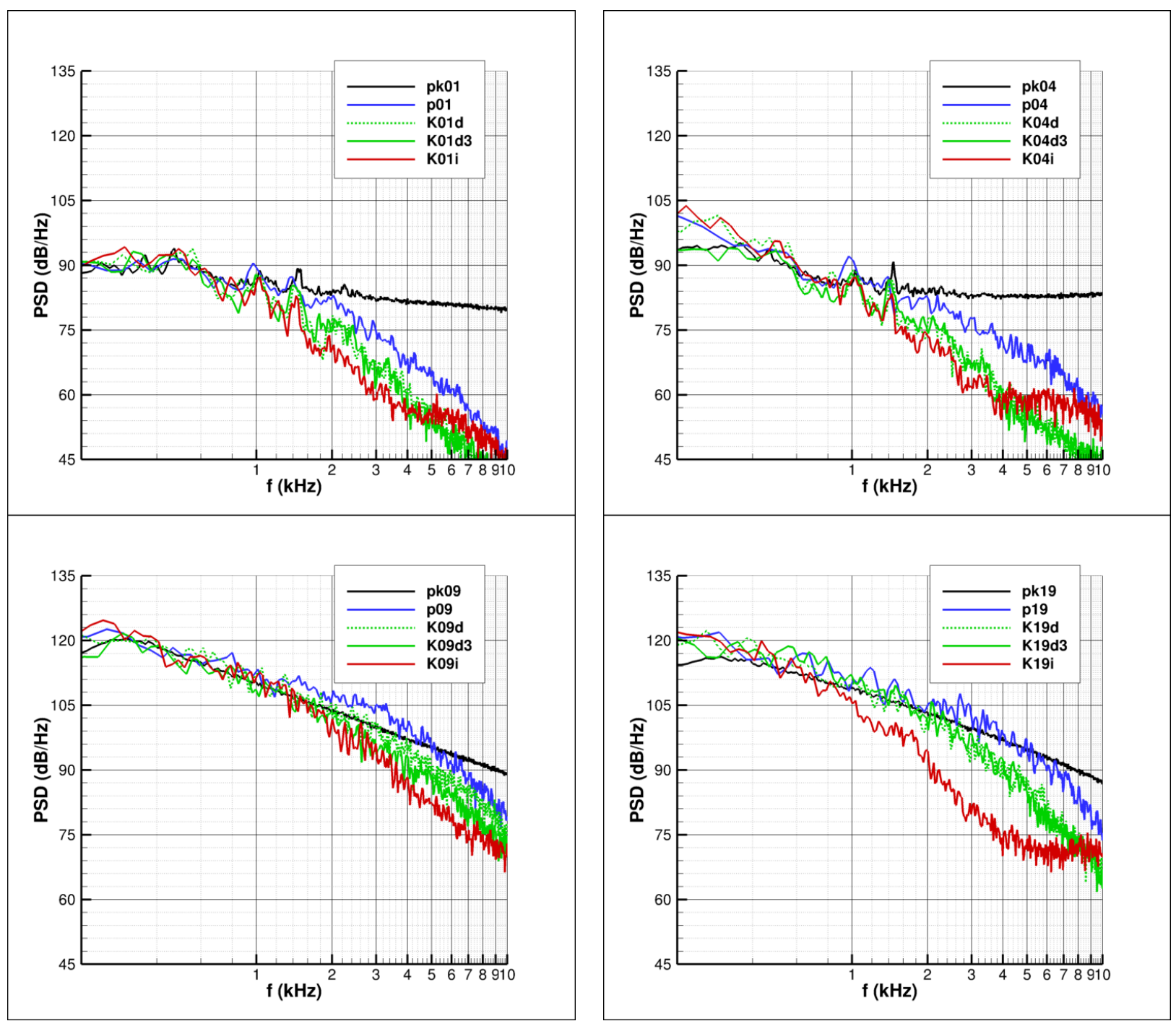

Figure 14: unsteady pressure PSD on the wheel. px , Kxd, Kxd3, Kxi: computations respectively on G1, OM12, OM13, OM22, pkx: measurements 

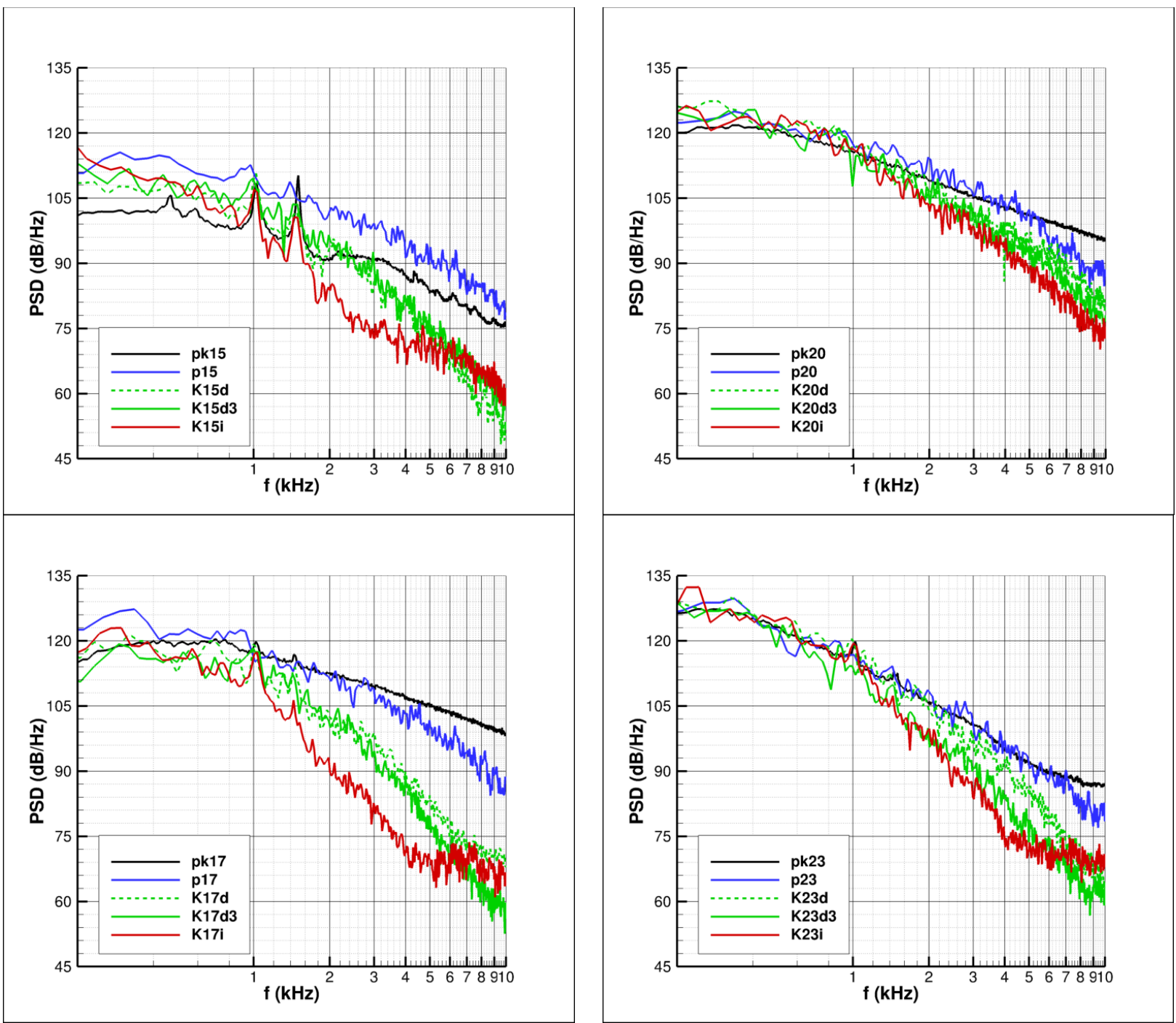

Figure 15: unsteady pressure PSD. px , Kxd, Kxd3, Kxi: computations respectively on G1, OM12, OM13, OM22, pkx: measurements

\section{Far field acoustic results}

In this section, the far field results will detailed and commented. Figure 16 and Figure 17 present the far field arc measurement locations, along the Fly Over and Side Line arcs. These arcs are centered at the wheel center and have a $6 \mathrm{~m}$ radius $(20 \mathrm{D}$, with $\mathrm{D}$ the wheel diameter). They comprise 12 microphones which are spaced by $10 \mathrm{deg}$. approximately.

During the computation, $120 \mathrm{~ms}$ of wall pressure data were stored on the skin of the landing gear. These data are input to the ONERA KIM code, to compute the far field at the fly-over (FO) and side-line (SL) microphones. 


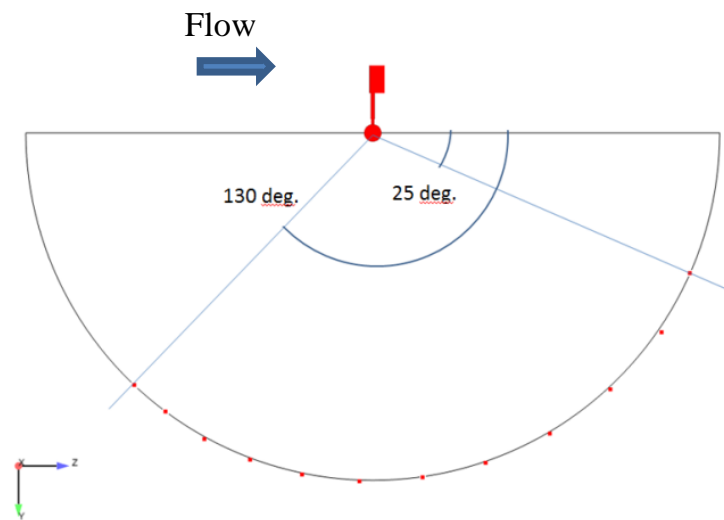

Figure 16: Far field microphones, Fly over arc.

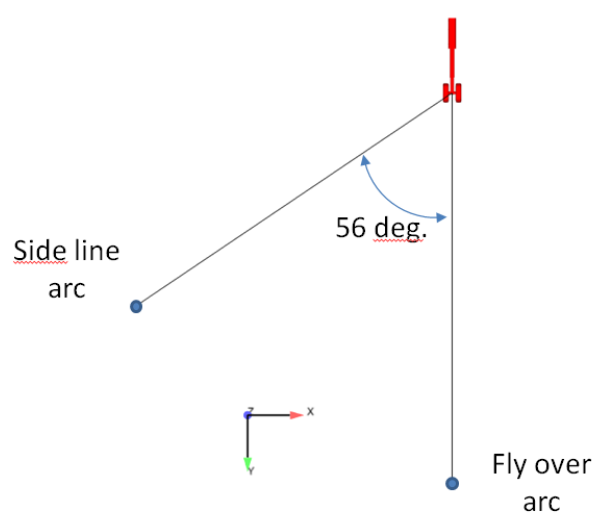

Figure 17: Far field microphones, Fly over and Side line arcs.

The acoustic far field results are illustrated by Figure 18 and Figure 19 presenting the far field results along the Fly Over arc, for the different grids. Despite the consistently lower cut-off frequency observed for the OM grids computations, already mentioned above, the results are quite encouraging. This reduced cut-off frequency can be explained by the octree definition around the landing gear that was not as fine as previous G1 or G2 grids, especially in the inter-wheel cavity and near field of the landing gear. This choice of aggressive grid cell count reduction, was made from the beginning, in line with the proof of concept objective assigned to the present computations. This can be easily handled in future works, once the feasibility of the proposed approach is established.

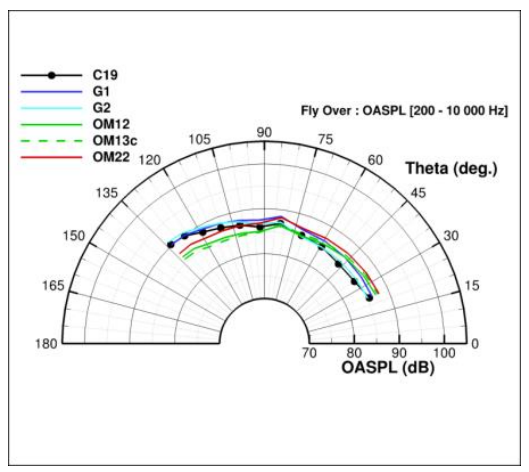

Figure 18: Fly over arc, comparison of computed and measured (black dots) OASPL

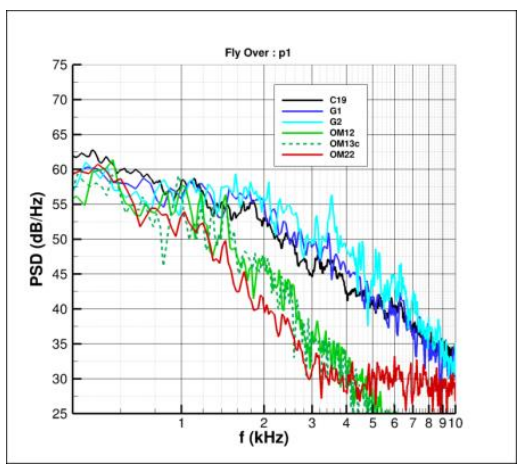

135 deg.

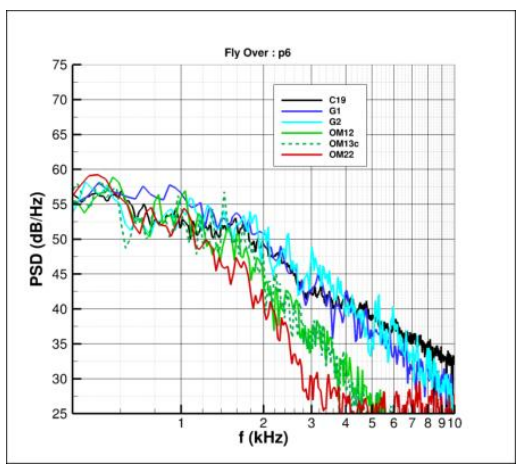

90 deg.

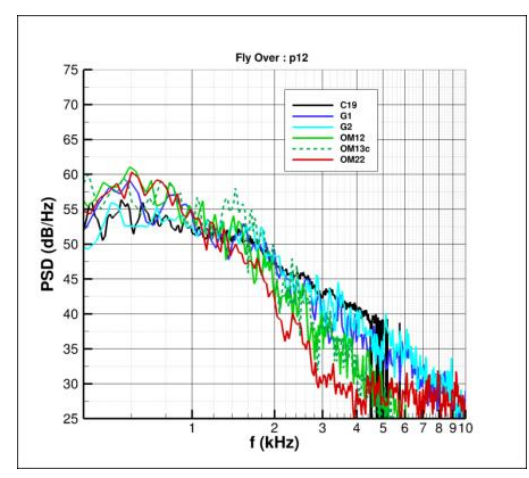

$25 \mathrm{deg}$.

Figure 19: comparison of computed and measured (black line) PSD of microphones on the Fly over arc 
The full paper will present and discuss the full acoustic results obtained in the course of the present effort.

\section{Acknowledgments}

The present work has been supported by internal grants from the ONERA scientific direction. The authors would like to thank E. Manoha from ONERA for fruitful discussions and help in conducting the present work. They also thank Airbus, ONERA and NASA for providing the LAGOON test case inside the BANC international workshop framework. Supports from $\mathrm{Ph}$. Grenard from ONERA in handling OM2i grid computations are kindly acknowledged by the first author.

\section{References}

[1] L. Sanders, E.Manoha, S. Ben Khelil, C. François "LAGOON: CFD/CAA coupling for Landing Gear Noise and Comparison with Experimental Database", AIAA 2011-2822, 17th AIAA/CEAS Aeroacoustics Conference, Portland, 6-8 June 2011

[2] E. Manoha, B. Caruelle, "Summary of the LAGOON solutions from the Benchmark problems for Airframe Noise Computations -III Workshop", in: 21 st AIAA/CEAS Aeroacoustics Conference, June 22-26, 2015, Dallas, Texas, USA, no. AIAA paper 2015-2846, 2015.

[3] F. Vuillot, F. Houssen, E. Manoha, S. Redonnet, J. Jacob, "Applications of the CEDRE unstructured flow solver to landing gear unsteady flow and noise predictions", AIAA 2011-2944, 17th AIAA/CEAS Aeroacoustics Conference, 6-8 June 2011, Portland, Oregon

[4] V. N. Vatsa, D. P. Lockard, M. R. Khorrami, J.-R. Carlson "Aeroacoustic Simulation of a Nose Landing Gear in an Open Jet Facility using FUN3D", 18th AIAA/CEAS Aeroacoustics Conference, 4 - 6 June 2012, Colorado Springs, CO

[5] F. de la Puente Cerezo, L. Sanders, F.Vuillot, P. Druault, E.Manoha, "Zonal Detached Eddy Simulation of a simplified nose landing-gear for flow and noise predictions using an unstructured Navier-Stokes solver", Journal of Sound and Vibration, 405, (2017), pp.86-111, doi: 10.1016/j.jsv.2017.05.046

[6] D. Casalino, A. F. P. Ribeiro, E. Fares, S. Nölting, "Lattice-Boltzmann Aeroacoustic Analysis of the LAGOON LandingGear Configuration," AIAA Journal 52 (2014) 1232-1248.

[7] M. Murayama, Y. Yokokawa, K. Yamamoto, T. Hirai, "Computational study of low-noise fairings around tire-axle region of a two-wheel main landing gear," Computers and Fluids 85 (2013) 114-124, international Workshop on Future of CFD and Aerospace Sciences.

[8] D. Mincu, T. Le Garrec, S. Peron, M. Terracol, "Immersed boundary conditions for high order CAA solvers Aeroacoustics installation effects, assessment," AIAA-2017-3504, 23rd AIAA/CEAS Aeroacoustics Conference, Denver, USA, 2017

[9] E. Manoha, J. Bulté, B. Caruelle, "LAGOON : an Experimental Database for the Validation of CFD/CAA Methods for Landing Gear Noise Prediction," AIAA paper 2008-2816, 14th AIAA/CEAS Aeroacoustics Conference, May 5-7, 2008, Vancouver, British Columbia, Canada, 2008.

[10] E. Manoha., J. Bulté, V. Ciobaca, B. Caruelle, "LAGOON : further analysis of aerodynamic experiments and early aeroacoustics results," AIAA 2009-3277 15th AIAA/CEAS Aeroacoustics Conference, May 11-13, 2009, Miami, Florida, USA, 2009.

[11] P. Chevalier, B. Courbet, D. Dutoya, P. Klotz, E. Ruiz, J. Troyes, P. Villedieu, "CEDRE: development and validation of a multiphysic computational software", 1st EUCASS, 4-7 July 2005, Moscow.

[12] A. Refloch, B. Courbet, A. Murrone, P. Villedieu, C. Laurent, P. Gilbank, J. Troyes, L. Tessé, G. Chaineray, J. Dargaud, E. Quémerais, F. Vuillot, "CEDRE software", in: CFD Platforms and coupling, Aerospace Lab, no. Issue 2, 2011.

[13] P. R. Spalart, S. Deck, M. L. Shur, K. D. Squires, M. K. Strelets, A. Travin, "A new version of detached-eddy simulation, resistant to ambiguous grid densities," Theoretical and Computational Fluid Dynamics 20 (3) (2006) 181-195.

[14] S. Deck, "Recent improvements in the zonal detached eddy simulation (ZDES) formulation," Theoretical and Computational Fluid Dynamics, 26 (6) (2012) 523-550.

[15] F. de la Puente, L. Sanders, F. Vuillot, "On LAGOON nose landing gear CFD-CAA computation over unstructured mesh using a ZDES approach", in: 20th AIAA/CEAS Aeroacoustics Conference, June 16-20, 2014, Atlanta, Georgia, USA, no. AIAA paper 2014-2763, 2014.

[16] F. de la Puente, L. Sanders, F. Vuillot, E. Manoha, "Nose landing gear flow and noise predictions on unstructured grid using a cell-centered Navier-Stokes code", in: 21st AIAA/CEAS Aeroacoustics Conference, June 22-26, 2015, Dallas, Texas, USA, no. AIAA paper 2015-3256, 2015.

[17] F. de la Puente, "Aeroacoustic simulations of landing gears with unstructured grids and a ZDES turbulence model", PhD thesis, Université Pierre et Marie Curie (UPMC-Paris VI), 12th October 2017

[18] J. Prieur, G. Rahier, "Aeroacoustic integral methods, formulation and efficient numerical implementation," Aerospace Science and Technology, Vol. 5, 2001, pp. 457-468. 
[19] G. Rahier, J. Prieur, F. Vuillot, N. Lupoglazoff, A. Biancherin, "Investigation Of Integral Surface Formulations For Acoustic Post-processing Of Unsteady Aerodynamic Jet Simulations", Aerospace Science and Technology, Volume 8, Issue 6, September 2004, pp. 453-467.

[20] C. Benoît, S. Peron, S. Landier, "Cassiopee: a CFD pre-and post-processing tool", Aerosp Sci Technol 2015;45: $272-243$.

[21] F. D. L. Puente, L. Sanders, F. Vuillot, E. Manoha, "Nose landing gear flow and noise predictions on unstructured grid using a cell-centered Navier-Stokes code," in: 21st AIAA/CEAS Aeroacoustics Conference, June 22-26, 2011, Dallas, Texas, USA, no. AIAA paper 2015-3256, 2015.

[22] M.-S. Liou, K.-H. Kao, "Progress in Grid Generation: From Chimera to DRAGON Grids", NASA Technical Memorandum 106709, ICOMP-94-19, 1994

[23] K.-H. Kao and M.-S. Liou. "Direct replacement of arbitrary grid-overlapping by nonstructured grid", AIAA paper 95-346, 33rd Aerospace Sciences Meeting and Exhibit, Aerospace Sciences Meetings, Reno, NV, U.S.A.

[24] S. Landier, "Boolean operations on arbitrary polygonal and polyhedral meshes", Computer-Aided Design, http://dx.doi.org/10.1016/j.cad.2016.07.013, 2016.

[25] F. Vuillot; F. de la Puente; S. Landier; T. Renaud; C. Benoit; L. Sanders, "New Unstructured Grid Strategies for Applications to Aeroacoustic Computations of the LAGOON, Landing Gear Model, Using the CEDRE Unstructured Flow Solver", AIAA-2017-3011, 23rd AIAA/CEAS Aeroacoustics Conference, Denver,USA, 2017. 